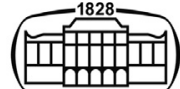

AKADÉMIAI KIADÓ

\title{
Comment on: Problematic online gaming and the COVID-19 pandemic - The role of exergames
}

\section{Journal of Behavioral Addictions}

$10(2021) 1,1-3$

DOI:

10.1556/2006.2021.00014

(C) 2021 The Author(s)
COMMENTARY

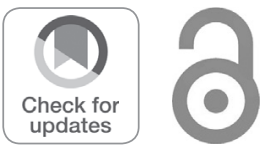

* Corresponding author. E-mail: andre.claudio@gmail.com

\author{
${ }^{1}$ Laboratório de Avaliação do Movimento Humano, Faculdade de Educação Física e Dança, \\ Universidade Federal de Goiás, Goiânia, Brazil \\ ${ }^{2}$ Escola Superior de Educação Física e Fisioterapia do Estado de Goiás, Universidade Estadual de \\ Goiás, Goiânia, Brazil \\ ${ }^{3}$ Centro de Educação Física e Desportos, Universidade Federal do Espírito Santo, Vitória, Brazil \\ ${ }^{4}$ Departamento de Fisiologia, Universidade Federal de São Paulo, São Paulo, Brazil
}

Received: October 19, 2020 • Revised manuscript received: January 14, 2021; February 15, 2021 • Accepted: February 22, 2021

Published online: March 4, 2021

\begin{abstract}
Although significant increases in gaming may not always be beneficial, exergames (a new generation of video games also known as exergaming or active video games) appear as an alternative, feasible, attractive, and safe way to perform physical exercise for most clinical and nonclinical populations. Therefore, it is important to recognize that exergames can be considered a useful tool for coping with the COVID-19 outbreak and the recommended social distancing period.
\end{abstract}

\section{KEYWORDS}

COVID-19, coronavirus, pandemic, active video game, exergaming

We read with great interest the recent letter to the editor "Problematic online gaming and the COVID-19 pandemic" (King et al., 2020) published in the Journal of Behavioral Addictions. The authors expressed their concern about the increase in online gaming due to stay-at-home mandates and quarantines related to the COVID-19 outbreak. Although significant increases in gaming may not always be beneficial (King, Koster, \& Billieux, 2019), we would like to call attention to a specific type of gaming - exergames. Exergames are an interesting way to play a video game while exercising that is both feasible and attractive for most clinical and nonclinical populations (Fung et al., 2010). Therefore, we offer a critical appraisal of the potential usage of exergames as a coping strategy for social isolation in a home-based environment during the COVID-19 outbreak and the recommended social distancing period.

Exergames, a new generation of video games also known as exergaming or active video games, are linked to the idea of integrating ample body movements (e.g., trunk, upper and/or lower limbs) (Staiano \& Calvert, 2011; Wiemeyer et al., 2015) with attractive digital games (Rizzo, Lange, Suma, \& Bolas, 2011; Wiemeyer et al., 2015). Visual and auditory stimuli are combined with different types of equipment (e.g., balance boards, steeping mats, dance mats, dumbbells, cameras, and other types of sensors and inputs) that allow users to move to play (Baracho, Gripp, \& Lima, 2012; Lieberman et al., 2011). Exergames, like traditional video games, can also be played in multiplayer mode, which can contribute to increasing social interaction in a home environment (O’Donovan et al., 2012; Peng \& Crouse, 2013). Currently, there are several types of exergames, such as those which simulate traditional aerobic exercises (e.g., walking, running, and cycling) (Graves et al., 2010; Wu, Wu, \& Chu, 2015), sports modalities (e.g., basketball, bowling, tennis, table tennis, baseball, swimming, 
ping-pong, volleyball, beach volleyball, and boxing), dancing (Neves et al., 2015; Unnithan, Houser, \& Fernhall, 2006; Viana et al., 2017), and weight-bearing exercises (Moreira, Rodacki, Costa, Pitta, \& Bento, 2020; Viana et al., 2018; Viana, Gentil, Andrade, Vancini, \& de Lira, 2019). Consoles that enable this experience are Sony's PlayStation Move ${ }^{\circledR}$, Microsoft's Xbox Kinect ${ }^{\circledR}$ and Nintendo's Wii ${ }^{\circledR}$ (Viana et al., 2020; Wiemeyer et al., 2015).

Compared to online gaming, exergames appear more advantageous because they induce acute and chronic beneficial physiological and psychological changes that are not typically found following traditional forms of sedentary video gaming. Most studies involving exergames have investigated their effects on behavioral, cognitive, psychological and physical outcomes (Benzing \& Schmidt, 2018; Viana et al., 2020). There is evidence that exergame interventions are able to improve physical activity levels (Fogel, Miltenberger, Graves, \& Koehler, 2010), the performance of daily activities (Neumann, Meidert, BarberàGuillem, Poveda-Puente, \& Becker, 2018; Zangirolami-Raimundo et al., 2019), muscle strength in older adults (Htut, Hiengkaew, Jalayondeja, \& Vongsirinavarat, 2018), heart rate (Graves et al., 2010; Neves et al., 2015; Rodrigues et al., 2015; Viana et al., 2017, 2018), oxygen consumption (Graves et al., 2010; Rodrigues et al., 2015; Viana et al., 2018), and energy expenditure in various populations (Graves et al., 2010; Rodrigues et al., 2015; Viana et al., 2018; Wu et al., 2015), improvements in body composition in children (Staiano, Abraham, \& Calvert, 2013), postural balance (Jorgensen, Laessoe, Hendriksen, Nielsen, \& Aagaard, 2013), cognitive function in older adults (Maillot, Perrot, \& Hartley, 2012), and anxiety disorders in different populations (Viana \& de Lira, 2020; Viana et al., 2017). Therefore, although access to exergames may be more limited than access to traditional video games, the benefits of this type of video games must be taken into account during the COVID19 outbreak due to its strong motivational ability. Exergames are great in increasing motivation for exercise (Peng \& Crouse, 2013), and physical exercise plays an important role in coping with the detrimental effects on health imposed by social isolation and lockdown, such as a decrease in physical activity levels and an increase in sedentary behavior.

In summary, while we applaud the manuscript by King, Delfabbro, Billieux, and Potenza (2020), it is also important to recognize that exergames can be considered a useful tool for coping with the negative consequences imposed by the COVID-19 outbreak and self-isolation period.

Funding sources: This study was funded by Fundação de Amparo à Pesquisa do Estado de Goiás-FAPEG/Brazil (grant no. 201210267001056) and by Conselho Nacional de Desenvolvimento Científico e Tecnológico-CNPq/Brazil (grant no. 405096/2016-0).

Authors' contribution: Author RBV wrote the first draft of the letter and all authors contributed to and have approved the final manuscript.
Conflict of interest: The authors report no financial or other relationship relevant to the subject of this article.

\section{REFERENCES}

Baracho, A. F. D. O., Gripp, F. J., \& Lima, M. R. De. (2012). Exergames and the school physical education in the digital culture. Revista Brasileira de Ciências Do Esporte, 34(1), 111126.

Benzing, V., \& Schmidt, M. (2018). Exergaming for children and adolescents: Strengths, weaknesses, opportunities and threats. Journal of Clinical Medicine, 7(11), 422.

Fogel, V. A., Miltenberger, R. G., Graves, R., \& Koehler, S. (2010). The effects of exergaming on physical activity among inactive children in a physical education classroom. Journal of Applied Behavior Analysis, 43(4), 591-600.

Fung, V., So, K., Park, E., Ho, A., Shaffer, J., Chan, E., et al. (2010). The utility of a video game system in rehabilitation of burn and nonburn patients: A survey among occupational therapy and physiotherapy practitioners. Journal of Burn Care and Research, 31(5), 768-775.

Graves, L. E., Ridgers, N. D., Williams, K., Stratton, G., Atkinson, G., \& Cable, N. T. (2010). The physiological cost and enjoyment of Wii Fit in adolescents, young adults, and older adults. Journal of Physical Activity and Health, 7(3), 393-401.

Htut, T. Z. C., Hiengkaew, V., Jalayondeja, C., \& Vongsirinavarat, M. (2018). Effects of physical, virtual reality-based, and brain exercise on physical, cognition, and preference in older persons: A randomized controlled trial. European Review of Aging and Physical Activity, 15(1), 10.

Jorgensen, M. G., Laessoe, U., Hendriksen, C., Nielsen, O. B. F., \& Aagaard, P. (2013). Efficacy of Nintendo Wii training on mechanical leg muscle function and postural balance in community-dwelling older adults: A randomized controlled trial. The Journals of Gerontology Series A: Biological Sciences and Medical Sciences, 68(7), 845-852.

King, D. L., Delfabbro, P. H., Billieux, J., \& Potenza, M. N. (2020). Problematic online gaming and the COVID-19 pandemic. Journal of Behavioral Addictions, 9(2), 184-186.

King, D., Koster, E., \& Billieux, J. (2019). Study what makes games addictive. Nature, 573(7774), 346-346.

Lieberman, D. A., Chamberlin, B., Medina, E., Franklin, B. A., Sanner, B. M., Vafiadis, D. K., et al.. (2011). The power of play: Innovations in getting active summit 2011. Circulation, 123(21), 2507-2516.

Maillot, P., Perrot, A., \& Hartley, A. (2012). Effects of interactive physical-activity video-game training on physical and cognitive function in older adults. Psychology and Aging, 27(3), 589-600.

Moreira, N. B., Rodacki, A. L. F., Costa, S. N., Pitta, A., \& Bento, P. C. B. (2020). Perceptive-cognitive and physical function in prefrail older adults: Exergaming versus traditional multicomponent training. Rejuvenation Research, rej.2020.2302, 1-7.

Neumann, S., Meidert, U., Barberà-Guillem, R., Poveda-Puente, R., \& Becker, H. (2018). Effects of an exergame software for older adults on fitness, activities of daily living performance, and quality of life. Games for Health Journal, 7(5), 341-346. 
Neves, L. E. D. S., Cerávolo, M. P. D. S., Silva, E., De Freitas, W. Z. Da Silva, F. F., Higino, W. P., et al. (2015). Cardiovascular effects of Zumba ${ }^{\circledR}$ performed in a virtual environment using XBOX Kinect. Journal of Physical Therapy Science, 27(9), 28632865.

O’Donovan, C., Hirsch, E., Holohan, E., McBride, I., McManus, R., \& Hussey, J. (2012). Energy expended playing Xbox Kinect ${ }^{\mathrm{TM}}$ and $\mathrm{Wii}^{\mathrm{TM}}$ games: A preliminary study comparing single and multiplayer modes. Physiotherapy, 98(3), 224-229.

Peng, W., \& Crouse, J. (2013). Playing in parallel: The effects of multiplayer modes in active video game on motivation and physical exertion. Cyberpsychology, Behavior, and Social Networking, 16(6), 423-427.

Rizzo, A. A., Lange, B., Suma, E. A., \& Bolas, M. (2011). Virtual reality and interactive digital game technology: New tools to address obesity and diabetes. Journal of Diabetes Science and Technology, 5(2), 256-264.

Rodrigues, G. A. A., Felipe, D. D. S., Silva, E., De Freitas, W. Z., Higino, W. P., Da Silva, F. F., et al. (2015). Acute cardiovascular responses while playing virtual games simulated by Nintendo $\mathrm{Wii}^{\circledR}$. Journal of Physical Therapy Science, 27(9), 2849-2851.

Staiano, A. E., Abraham, A. A., \& Calvert, S. L. (2013). Adolescent exergame play for weight loss and psychosocial improvement: A controlled physical activity intervention. Obesity, 21(3), 598601.

Staiano, A. E., \& Calvert, S. L. (2011). Wii tennis play for low-income african american adolescents' energy expenditure. Cyberpsychology, 5(1), 4.

Unnithan, V., Houser, W., \& Fernhall, B. (2006). Evaluation of the energy cost of playing a dance simulation video game in overweight and non-overweight children and adolescents. International Journal of Sports Medicine, 27(10), 804-809.
Viana, R. B., Alves, C. L., Vieira, C. A., Vancini, R. L., Campos, M. H., Gentil, P., et al. (2017). Anxiolytic effects of a single session of the exergame Zumba ${ }^{\circledR}$ Fitness on healthy young women. Games for Health Journal, 6(6), 365-370.

Viana, R. B., Dankel, S. J., Loenneke, J. P., Gentil, P., Vieira, C. A., Andrade, M. dos S., et al. (2020). The effects of exergames on anxiety levels: A systematic review and meta-analysis. Scandinavian Journal of Medicine \& Science in Sports, sms.13654.

Viana, R. B., \& de Lira, C. A. B. (2020). Exergames as coping strategies for anxiety disorders during the COVID-19 quarantine period. Games for Health Journal, 9(3), 147-149.

Viana, R. B., Gentil, P., Andrade, M. S., Vancini, R. L., \& de Lira, C. A. B. (2019). Is the energy expenditure provided by exergames valid? International Journal of Sports Medicine, 40(09), 563568.

Viana, R. B., Vancini, R. L., Vieira, C. A., Gentil, P., Campos, M. H., Andrade, M. S., et al. (2018). Profiling exercise intensity during the exergame Hollywood Workout on XBOX 360 Kinect $^{(\mathbb{P}}$. PeerJ, 6, e5574.

Wiemeyer, J., Deutsch, J., Malone, L. A., Rowland, J. L., Swartz, M. C., Xiong, J., et al. (2015). Recommendations for the optimal design of exergame interventions for persons with disabilities: Challenges, best practices, and future research. Games for Health Journal, 4(1), 58-62.

Wu, P. T., Wu, W. L., \& Chu, I. H. (2015). Energy expenditure and intensity in healthy young adults during exergaming. American Journal of Health Behavior, 39(4), 557-561.

Zangirolami-Raimundo, J., Raimundo, R. D., da Silva, T. D., de Andrade, P. E., Benetti, F. A., da Silva Paiva, L., et al. (2019). Contrasting performance between physically active and sedentary older people playing exergames. Medicine, 98(5), e14213. 